\title{
Synthesis and Application of Eco-Friendlyred Onion Skins Azo Dyes for the Removal of Cobalt from Aqueous Media
}

\author{
Gervais Manizabayo ${ }^{1 *}$, Aimable Niyomugabo ${ }^{2}$, Dr. Uche John Chukwu ${ }^{3}$ \\ ${ }^{1}$ Chemistry Department, College of Science and Technology, University of Rwanda, Rwanda \\ ${ }^{2}$ Chemical Engineering Department, African Center of Excellence for Sustainable Mining, Copperbelt University, Zambia \\ ${ }^{3}$ Pure and Industrial Chemistry Department, University of Port Harcourt, Nigeria
}

\begin{abstract}
The present study investigated the synthesis of low cost and environmental friendly red onion skins azo dyes derivatives and their application as ligands for the extraction of cobalt (II) ions from aqueous media. The effect of $\mathrm{pH}$, agitation time, ligand concentration, and metal ion concentration on $\mathrm{Co}^{2+}$ ions removal efficiency as well as the stoichiometric coefficients were examined. The study revealed that the azo dyes were effective in removing $\mathrm{Co}^{2+}$ ion from aqueous solution. The highest removal efficiencies were obtained within the $\mathrm{pH}$ ranges $6-7$. The results also showed that the \% extraction (\% $\mathrm{E}$ ) of $\mathrm{Co}^{2+}$ ions increased with agitation time and concentration of the ligand. The slope analysis carried out on the experimental data demonstrated that $\mathrm{Co}^{2+}$ ions reacted with the ligands in 1:2 metals to ligand ratio.
\end{abstract}

Keywords: Extraction, red onion skin, azo dyes, quercetin, $\mathrm{Co}^{2+}$ ions.

\section{INTRODUCTION}

C obalt ion $\left(\mathrm{Co}^{2+}\right)$ is among inorganic compounds formed from metals known as transitional metals. Like other heavy metals, most of cobalt ions find their way into the environment through waste waters discharged from nuclear power plants as well as mining, electroplating, pigment, metallurgical, electronic and paint industries[1], [2]. While cobalt ions are biologically necessary and an essential component vitamin B12 and cobalamins which play role in red blood cells production[3], the exposure to high level of $\left(\mathrm{Co}^{2+}\right)$ has been reported to cause various health effects such vomiting, nausea, paralysis, vision problem, lung irritation, sterility, hair loss, thyroid, low blood pressure, bone defects and diarrhea [1], [2]. Therefore, it is important to detect and remove cobalt (II) ions from wastewater prior to their discharge into the environment.

Over the years, different methods including chemical precipitation, membrane separation, ion exchange, adsorption and many others has been used in the recovery of in trace of heavy metals from aqueous media [4]-[10]. However, it has been reported that these methods are very expensive and consume a lot of energy [11]. On the other hand, studies have revealed that solvent extraction could contribute to energy saving in extraction of valuable materials from waste sludge (Mansur, Marcelo Borges., 2011). On the other hand, solvent extraction presents downsides which include the emulsion formation, dissolving of unwanted materials and loss of some compounds. The successful application of solvent extraction for the extraction of heavy metals for aqueous media requires the use of ligands that can interact with the metal ions to form insoluble compounds.

Research has shown that aromatic azo compounds have the ability to form stable complexes with transition metal due to the presence of the azo groups $(-\mathrm{N}=\mathrm{N}-)$, oxygen heteroatoms as well as the aromatic rings [12]-[15].A recent study carried out by Akaho and his coworkers showed that red onion skin extract (ROSE) azo compounds can form stable complexes with $\mathrm{Cu}^{2+}$ ions [16]. This suggests that these azo compounds could be used as low-cost ligands for the extraction of heavy metals such as copper, cobalt, zinc, iron, nickel and many others from aqueous media.

Therefore, the purpose of this study is to synthesize and evaluate the efficiency of red onion skins azo compounds as low cost and environmental friendly ligands for the extraction of $\mathrm{Co}^{2+}$ ions from wastewater.

\section{MATERIALS AND METHODS}

\section{II.1. Reagents and solutions}

All chemicals used for this study were of analytical grade, and they include Aniline $\left(\mathrm{C}_{6} \mathrm{H}_{5} \mathrm{NH}_{2}\right)$, sodium nitrite $\left(\mathrm{NaNO}_{2}\right)$, sodium hydroxide $(\mathrm{NaOH})$, hydrochloric acid $(\mathrm{HCl})$, and cobalt sulphate heptahydrate $\left(\mathrm{CoSO}_{4} \cdot 7 \mathrm{H}_{2} \mathrm{O}\right)$.

\section{II.2. Collection, pretreatment and extraction of red onion skin}

The red onion skins (Allium cepa) were collected from Oil Mil market, Port Harcourt, Nigeria. The skins were sun-dried and grinded into powder form prior the extraction process. Then, 200 grams of powdered red onion skins $(355 \mu \mathrm{m})$ was soaked into $500 \mathrm{ml}$ of the acetone for 48 hours. Afterward, the acetone soluble extracts were filtered off using Whatsman filter paper (pore size: $12 \mu \mathrm{m}$ ) and the filtrate evaporated in a water bath regulated at $50^{\circ} \mathrm{C}$. The extracts obtained after evaporating the solvent was further evaporated under ambient temperature for a couple of days, and then kept inside a desiccator to avoid absorption of moisture. 


\section{II.3. Synthesis of red onion skin azo dye ligands}

Two red onion skin azo dyes, aniline modified red onion skin extract (AmROSE) and aminophenol modified red onion skin extract (APmROSE) azo dyes were synthesized through diazotization and coupling processes. Aminophenol and aniline were first diazotized following the method described by [17]. Then, the diazonium salts obtained were coupled with "quercetin rich" red onion skin extract. The route for the synthesis and proposed structures of quercetin rich red onion skin azo dyes is shown in figure 1.

\section{II4. Extraction of Co(II) ions and stoichiometric analysis}

The extraction of copper (II) ions was carried out by shaking together $2 \mathrm{~mL}$ of the aqueous phase of known $\mathrm{pH}$ containing the metal ions and $2 \mathrm{~mL}$ of the ligand solution. After shaking, the two phases were allowed to settle. Afterward, $1 \mathrm{~mL}$ solution was pipetted from the lower (aqueous) phase, diluted with $4 \mathrm{ml}$ of distilled water and sent for AAS analysis to determine the concentration of $\mathrm{Co}^{2+}$ ions remaining in the aqueous phase. The $\%$ extraction of $\mathrm{Co}^{2+}$ ions at different $\mathrm{pH}$, agitation time, ligand concentration and initial metal ions concentration were determined. The slope analysis was carried out by plotting the results of $\log \mathrm{D}$ vers $\log [\mathrm{Co}(\mathrm{II})]$ and $\log \mathrm{D}$ vers $\log [\mathrm{HL}]$, where $\mathrm{D}$ and $[\mathrm{HL}]$ are the distribution ratio and ligand concentration respectively.

\section{III.RESULTS AND DISCUSSIONS}

\section{III.1. Effect of $p H$}

The effect of $\mathrm{pH}$ on the extraction of $\mathrm{Co}^{2+}$ ions using the synthesized dyes is shown by figure 3.1. It can be observed that within the $\mathrm{pH}$ range of 1.27 to 4.86 , the extraction efficiency (\% E) of $\mathrm{Co}^{2+}$ using AmROSE azo dye increased gradually with $\mathrm{pH}$ before it started dropping. The results also showed a rapid increase in extraction efficiency of $\mathrm{Co}^{2+}$ ions using APmROSE azo dye within the $\mathrm{pH}$ range of 3.5 to 6.5. Overall, there was no consistent trend observed, however, the highest \% extraction efficiencies were observed within the $\mathrm{pH}$ range of 6-7 for both AmROSE and APmROSE azo dyes.

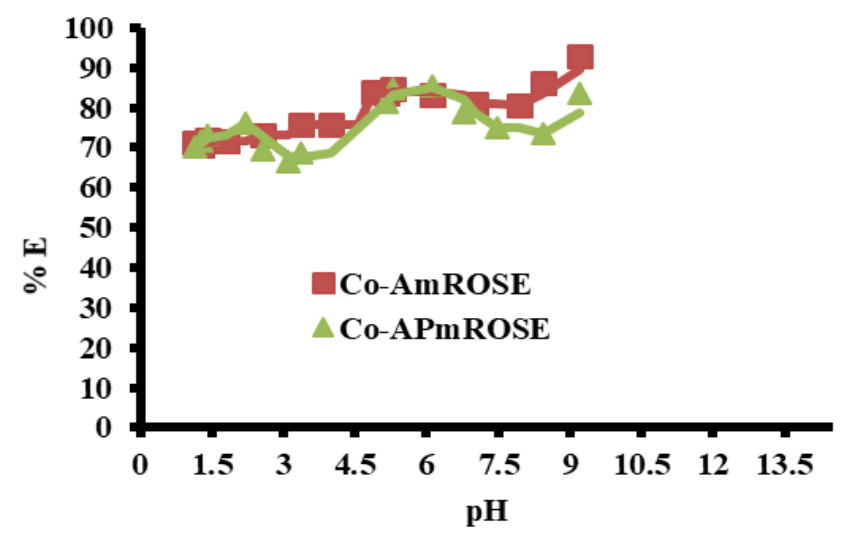

Fig 3.1: Variation of percent extraction efficiency (\% E) with $\mathrm{pH}$
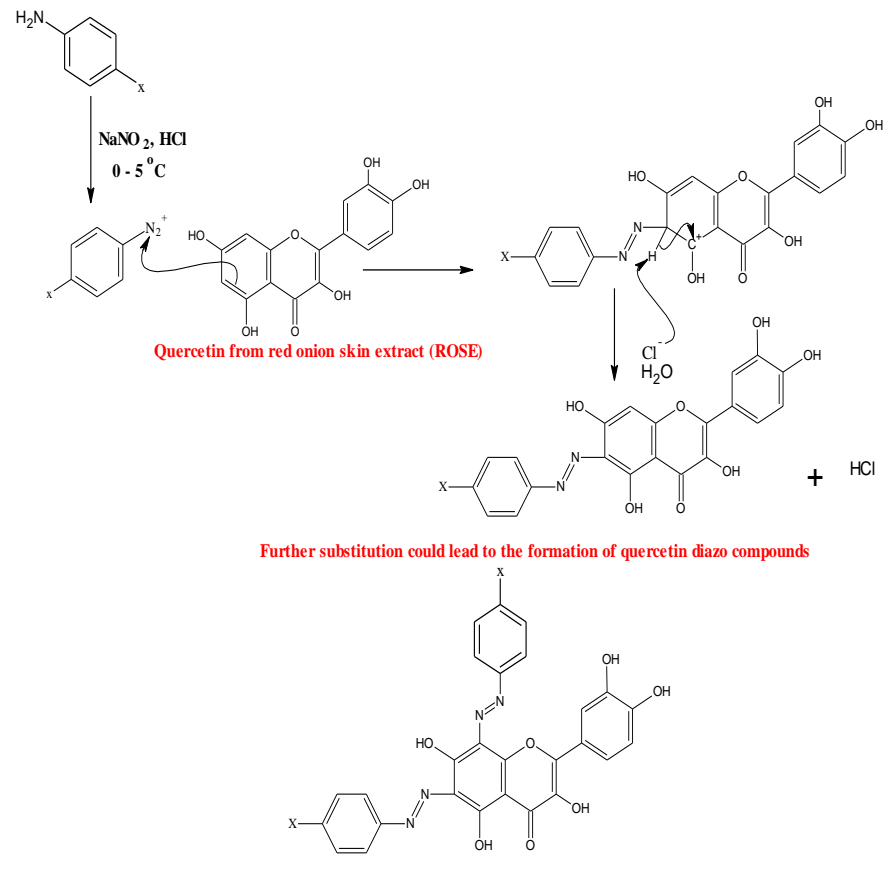

$\mathrm{x}=\mathrm{H}$ for aniline and $\mathrm{x}=\mathrm{OH}$ for aminophenol

Scheme 1: Route for the synthesis of flavonoid azo compounds [17]

\section{III.2. Effect of agitation time}

The effect of agitation time on the $\% \mathrm{E} \mathrm{n}$ of $\mathrm{Co}^{2+}$ using AmROSE and APmROSE was studied and the results are displayed in figure 3.2. The results show that the $\% \mathrm{E}$ of $\mathrm{Co}^{2+}$ using AmROSE and APmROSE azo dyes increased with agitation time. The results demonstrated that by increasing the agitation time from 10 to 50 minutes, the $\%$ extraction efficiency of $\mathrm{Co}^{2+}$ increased from $90.3 \%$ and $93.2 \%$ to 98.2 $\%$ and $99.8 \%$ using AmROSE and APmROSE respectively. This observation was in agreement with the results reported by preview researchers [10], [18]-[20].However, there was no significant change in \% Extraction between the last 40 and 50 minutes, and this is possibly because the ligand active sites had been exhausted [18].

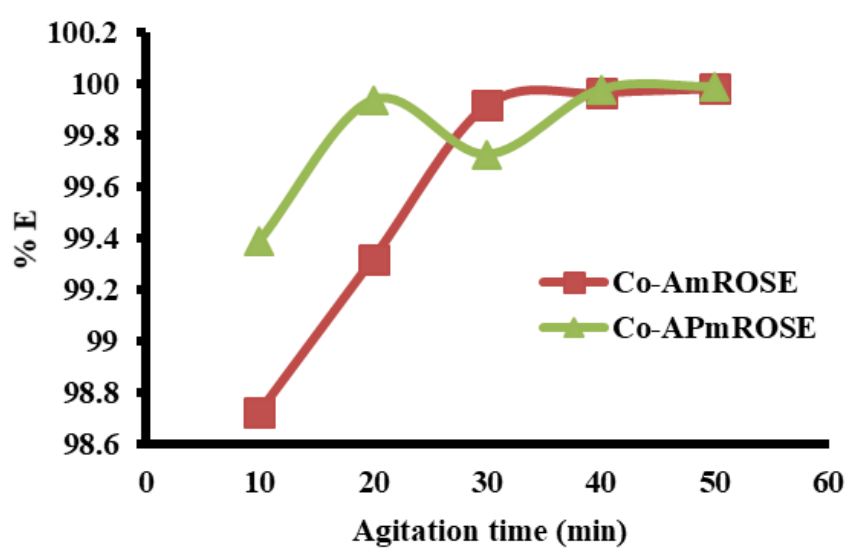

Fig 3.2: Variation of percent extraction efficiency (\% E) with agitation time 


\section{II.3. Effect of initial metal ions concentration}

The effect of initial concentration of $\mathrm{Co}^{2+}$ ions on the $\% \mathrm{E}$ is shown in figure 3.3. The figure reveals that increasing the in initial concentration of the metal ions from 10 to $50 \mathrm{ppm}$ had no significant effect on the \% $\mathrm{E}$. This is possibly because the active sites of the AmROSE and APmROSE had already been saturated at $10 \mathrm{ppm}$ of the metal ions [7]. This means that at $10 \mathrm{ppm}$ of $\mathrm{Co}^{2+}$ ion, the ligands had achieved their maximum adsorption capacity. Therefore, the initial concentration showed no effect on the overall percentage extraction efficiency of $\mathrm{Co}^{2+}$ ions using APmROSE and AmROSE ligands.

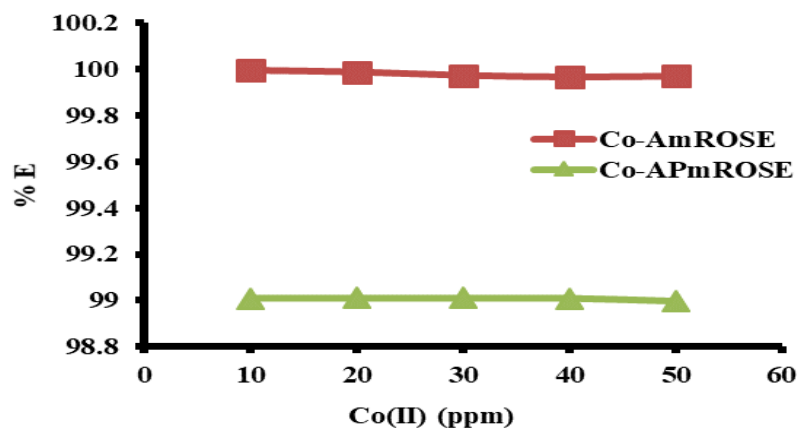

Fig 3.3: Effect of initial concentration of $\mathrm{Co}^{2+}$ ions on the $\% \mathrm{E}$.

III.4. Effect of azo dyes (ligand) concentration on the \% E removal

The results on the effect of red onion azo dye concentration of the percent extraction efficiency of $\mathrm{Co}^{2+}$ ions are displayed in figure 3.4. It can be deduced that the extraction efficiency of $\mathrm{Co}^{2+}$ gradually increases with concentration of the azo dyes before reaching the optimum $\% \mathrm{E}$. The increase in the $\% \mathrm{E}$ with concentration of the ligand may be attributed to the presence of more coordination sites available for binding the metal ions [21]-[23].This was in agreement with the observations made by preview authors [22][9]. The results also showed that at ligand concentration higher than $0.01 \mathrm{M}$, the percentage removal efficiency of $\mathrm{Co}^{2+}$ was nearly constant, and this is possibly as a result of the depletion of all $\mathrm{Co}^{2+}$ ion that were initially present in the medium [7].

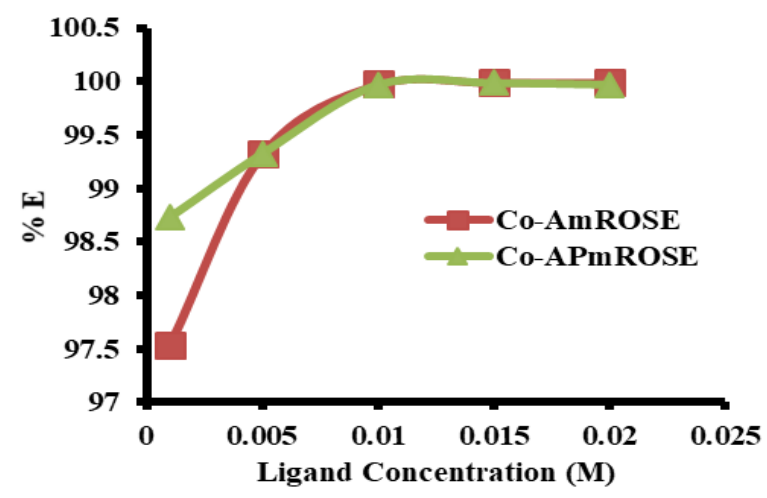

Fig 3.4: Effect of ligand concentration on the $\% \mathrm{E}$ of $\mathrm{Co}^{2+}$

\section{III.5. Slope analysis for the extraction of $\mathbf{C o}^{2+}$ ions}

The stoichiometric coefficients between $\mathrm{Co}^{2+}$ and the azo dye ligands were obtained by using slope analysis as presented in figures3.5 and 3.6. The stoichiometric coefficients for the metal ions and ligands are presented in table 1 , and it can be inferred that approximately $2 \mathrm{~mol}$ of the ligands were involved in the reaction with one mole of the $\mathrm{Co}^{2+}$ ions. This suggests that $\mathrm{Co}^{2+}$ and the azo dye ligands reacted in a molar ratio of 1:2 as represented by equations 3.10-3.12.

Table 1: Stoichiometric coefficients for the metal ion and ligands

\begin{tabular}{|c|c|c|}
\hline & Co-AmROSE & Co-APmROSE \\
\hline $\mathrm{m}-1$ & -0.0233 & -0.0158 \\
\hline $\mathrm{m}$ & 0.9767 & 0.9842 \\
\hline $\mathrm{n}$ & 2.0303 & 1.7754 \\
\hline
\end{tabular}

Where m: Mole of $\mathrm{Co}^{2+}$ ions ; and n: Mole of the red onion skin azo dye.

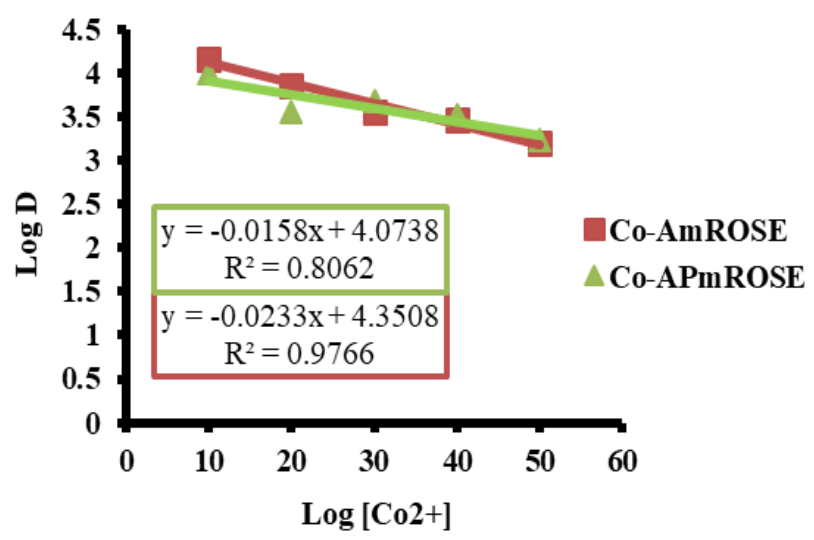

Fig 3.5: Plot of $\log \mathrm{D}$ versus $\log \left[\mathrm{Co}^{2+}\right]$

$$
\begin{gathered}
\mathrm{Co}^{2+}+2 \text { UROSE } \rightleftharpoons \mathrm{Co}-\text { UROSE }+2 \mathrm{H}^{+}(\mathbf{3 . 1 0}) \\
\mathrm{Co}^{2+}+2 \mathrm{AmROSE} \rightleftharpoons \mathrm{Co}-\mathrm{AmROSE}+2 \mathrm{H}^{+}(\mathbf{3 . 1 1}) \\
\mathrm{Co}^{2+}+2 \mathrm{APmROSE} \rightleftharpoons \mathrm{Co}-\mathrm{APmROSE}+2 \mathrm{H}^{+}(\mathbf{3 . 1 2})
\end{gathered}
$$

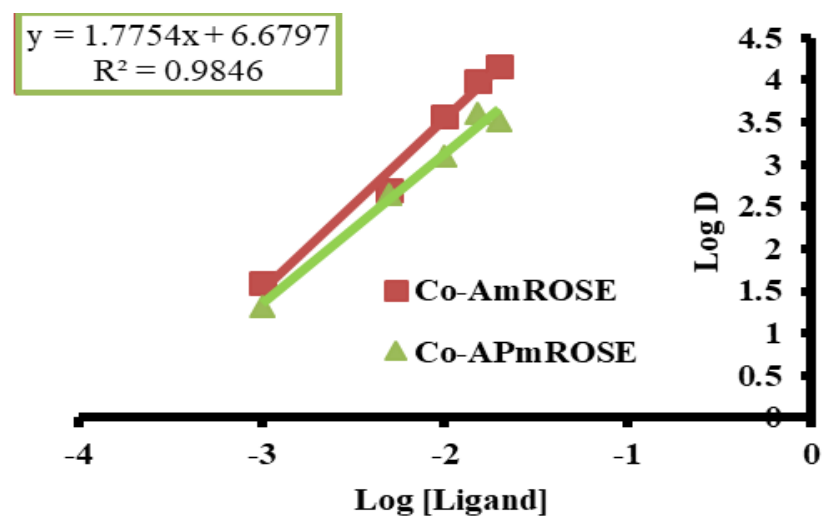

Fig 3.6: Plot of $\log \mathrm{D}$ versus $\log$ [Ligand] 


\section{CONCLUSION}

Red onion skin azo dyes has been successfully synthesized and applied for the removal of $\mathrm{Co}^{2+}$ ions from aqueous media. The percent extraction efficiency of the metal varied significantly with $\mathrm{pH}$ of the medium as well as the agitation time, ligands concentration and initial concentration of $\mathrm{Co}^{2+}$ ions in the medium. The slope analysis of the experimental results revealed that the azo dyes reacted with the $\mathrm{Co}^{2+}$ ions in a 1:2 metal-to-ligand molar ratio.

\section{ACKNOWLEDGMENT}

The authors wish to acknowledge the support of Prof. Ovi Julius Abayeh for his support for the success of this research.

\section{REFERENCES}

[1] S. S. Al-Shahrani, "Treatment of wastewater contaminated with cobalt using Saudi activated bentonite," Alexandria Eng. J., pp. 18, 2015, doi: 10.1016/j.aej.2013.10.006.

[2] S. Tizro and H. Baseri, "article original Removal of Cobalt Ions from Contaminated Water Using Magnetite Based Nanocomposites: Effects of Various Parameters on the Removal Efficiency," J. Water Environ. Nanotechnol, vol. 2, no. 3, pp. 174185, 2017, doi: 10.22090/jwent.2017.03.005.

[3] L. Laura, V. Bart, V. D. S. Catherine, and W. Floris, "Cobalt toxicity in humans. A review of the potential sources and systemic health effects," Toxicology, vol. 387, pp. 43-56, 2017, doi: 10.1016/j.tox.2017.05.015.

[4] K. Ahmad, I. A. Bhatti, M. Muneer, M. Iqbal, and Z. Iqbal, "Removal of heavy metals $(\mathrm{Zn}, \mathrm{Cr}, \mathrm{Pb}, \mathrm{Cd}, \mathrm{Cu}$ and $\mathrm{Fe})$ in aqueous media by calcium carbonate as an adsorbent," nternational J. Chem. Biochem. Sci., vol. 2, pp. 48-53, 2012.

[5] Hala Ahmed Hegaz, "Removal of heavy metals from wastewater using agricultural and industrial wastes as adsorbents," Sci. Direct, pp. 1-16, 2017.

[6] F. Fu and Q. Wang, "Removal of heavy metal ions from wastewaters : A review," J. Environ. Manage., vol. 92, no. 3, pp. 407-418, 2011, doi: 10.1016/j.jenvman.2010.11.011.

[7] B. W. Waweru, I. W. Mwangi, J. Murungi, R. N. Wanjau, and R. Manohah, "Remediation of Lead, Cadmium and Copper Polluted Waters by Onion Skins ( Allium Cepa )," vol. 4, no. 5, pp. 932943, 2016.

[8] A. K. Dwivedi, D. Pratap, and S. Rajput, "studies on adsorptive removal of heavy metal $(\mathrm{Cu}, \mathrm{Cd})$ from aqueous solution by tea waste adsorbent," J. Ind. Pollut. Control, vol. 30, no. 1, pp. 85-90, 2014.

[9] S. Jena and R. K. Sahoo, "Removal of Pb ( II ) from Aqueous Solution Using Fruits Peel as a Low Cost Adsorbent," Eng. Technol., vol. 5, no. 1, pp. 1-9, 2017.

[10] A. M. Etorki, M. El-rais, and M. T. Mahabbis, "Removal of Some
Heavy Metals from Wastewater by Using of Fava Beans," Am. J. Anal. Chem., vol. 5, pp. 225-234, 2014.

[11] A. Tripathi and M. R. Ranjan, "Bioremediation \& Biodegradation Heavy Metal Removal from Wastewater Using Low Cost Adsorbents," Bioremediation Biodegrad., vol. 6, no. 6, 2015, doi: 10.4172/2155-6199.1000315.

[12] O. E. Oyeneyin, "Journal of Recent Research and Applied Studies," J. Recent Res. Appl. Stud., pp. 1-7, 2019.

[13] Y. Abboud et al., "A novel azo dye, 8-quinolinol-5-azoantipyrine as corrosion inhibitor for mild steel in acidic media," Desalination, vol. 237, no. 1-3, pp. 175-189, 2009, doi: 10.1016/j.desal.2007.12.031.

[14] H. Shokry, "Molecular dynamics simulation and quantum chemical calculations for the adsorption of some Azo-azomethine derivatives on mild steel," J. Mol. Struct., vol. 1060, no. 1, pp. 80-87, 2014, doi: 10.1016/j.molstruc.2013.12.030.

[15] L. H. Madkour, S. Kaya, C. Kaya, and L. Guo, "Quantum chemical calculations, molecular dynamics simulation and experimental studies of using some azo dyes as corrosion inhibitors for iron. Part 1: Mono-azo dye derivatives," J. Taiwan Inst. Chem. Eng., vol. 68, pp. 461-480, 2016, doi: 10.1016/j.jtice.2016.09.015.

[16] A. A. Akaho, U. J. Chukwu, and O. Akaranta, "Cu (II)-Red Onion Skin Extract-Azo metal Complex - A Potential for Oilfield Applications," Chem. Sci. Int. J., vol. 26, no. 2, pp. 1-7, 2019, doi: $10.9734 / \mathrm{csji} / 2019 / \mathrm{v} 26 \mathrm{i} 230086$.

[17] G. Manizabayo, U. J. Chukwu, and O. J. Abayeh, "Extraction of 'Quercetin-Rich' Red Onion Skin with Acetone and Chemical Modification using Aromatic Diazonium Salts," Makara J. Sci., vol. 23, no. 2, 2019, doi: 10.7454/mss.v23i2.11045.

[18] K. M. El Moselhy, M. A. Azzem, A. Amer, and A. E. Al Prol, "Adsorption of Cu ( II ) and Cd ( II ) from Aqueous Solution by Using Rice Husk Adsorbent," vol. 12, no. Ii, pp. 1-13, 2017.

[19] I. Nhapi, N. Banadda, R. Murenzi, C. B. Sekomo, and U. G. Wali, "Removal of Heavy Metals from Industrial Wastewater Using Rice Husks," pp. 170-180, 2011.

[20] M. Cheraghi, S. Sobhanardakani, R. Zandipak, and B. Lorestani, "Removal of $\mathrm{Pb}$ ( II ) from Aqueous Solutions Using Waste Tea Leaves," vol. 9, no. 28, 2015.

[21] S. Ayub and F. Changani, "Adsorpton process for wastewater treatment by coconut shell," Int. J. Civil, Struct. Environ. Infrastracture Eng., vol. 4, no. 3, pp. 21-34, 2014.

[22] M. Lamsayah, M. Khoutoul, A. Takfaoui, and R. Touzani, "High liquid - liquid extraction selectivity of Fe ( II ) and $\mathrm{Pb}$ ( II ) with TD-DFT theoretical calculations of long chain acid pyrazole- and triazole-based ligands High liquid - liquid extraction selectivity of Fe ( II ) and," Cogent Chem., vol. 90, no. 2, pp. 1-16, 2016, doi: 10.1080/23312009.2016.1230359.

[23] A. Kaushal and S. Sk, "Adsorption Phenomenon and Its Application in Removal of Lead from Waste Water: A Review," Int. J. Hydrol., vol. 1, no. 2, pp. 1-11, 2017, doi: 10.15406/ijh.2017.01.00008. 